\title{
GÊNERO E SERVIÇO SOCIAL NA RÁDIO UNIVERSIDADE: A EXPERIÊNCIA POR MEIO DO PROGRAMA "SOCIAL EM QUESTÃO"
}

GENDER AND SOCIAL SERVICE IN THE RADIO UNIVERSITY: THE EXPERIENCE THROUGH

THE PROGRAM "SOCIAL IN QUESTION

\section{Eliana Mourgues Cogoy', Zaida Castro de Siqueira ${ }^{2}$}

RECEBIDO EM: 10/07/2017 / APROVADO EM: 17/08/2017

DOI: $10.5902 / 2317175828060$

\section{RESUMO}

A temática gênero pode ser compreendida como transversalmente relacionada a todos os segmentos da sociedade capitalista na qual estamos inseridos. Apresenta-se neste estudo, uma perspectiva do Serviço Social sobre o tema, que teve por base a experiência adquirida por meio do programa radiofônico "Social em Questão". O referido Programa caracteriza-se como projeto de extensão vinculado ao Núcleo de Estudos, Pesquisa e Extensão em Serviço Social, Mídia, Cultura e Questão Social (NEPMQS), pertencente ao Curso de Serviço Social da Universidade Federal de Santa Maria- UFSM. Para esse estudo, procura-se apresentar a importância do debate sobre gênero veiculado por meio dos programas radiofônicos do "Social em Questão".

Palavras Chave: Gênero; Serviço Social; Rádio; Extensão. 
GÊNERO E SERVICCO SOCIAL NA RÁDIO UNIVERSIDADE:

A EXPERIÊNCIA POR MEIO DO PROGRAMA "SOCIAL EM QUESTÃO"

\begin{abstract}
The gender theme can be understood as transversally related to all segments of capitalist society and traditionally patriarchal model, in which we are inserted. This study presents a perspective from the perspective of Social Service, based on the experience acquired through the radio program "Social in question". This program is an extension project linked to the Nucleus of Studies, Research and Extension in Social Service, Media, Culture and Social Issues (NEPMQS) belonging to the Social Service Course of the Federal University of Santa Maria - UFSM. In this sense, the importance of the debate and the deconstruction of myths and prejudices about gender equality are highlighted.
\end{abstract}

Keywords: Gender; Social Service; Radio; Extension.

\title{
1 INTRODUÇÃO
}

O presente trabalho é fruto de reflexões sobre a importância da discussão da temática "gênero" no programa radiofônico "Social em Questão", projeto de extensão do Núcleo de Estudos, Pesquisa e Extensão em Serviço Social, Mídia, Cultura e Questão Social (NEPMQS) vinculado ao Departamento de Serviço Social da Universidade Federal de Santa Maria - UFSM. Dessa forma, pretende-se elencar a importância do debate sobre o tema em questão, por meio do rádio, propiciado pelas falas de profissionais e acadêmicos das mais diversas áreas do conhecimento. Apresenta-se, também, a relação da interdisciplinaridade entre Comunicação e Serviço Social, bem como a transversalidade das duas áreas do conhecimento em todos os aspectos do fazer profissional, para além do espaço investigado, no caso, o programa "Social em Questão", além de ressaltar a importância do rádio como meio de comunicação de massa que até os dias atuais possui facilidade de acesso, de uso e de transporte.

\section{O CONCEITO DE GÊNERO A PARTIR DE UMA PERSPECTIVA CRÍTICA}

O termo "gênero" começou a ser utilizado entre as décadas de 1970 e 1980, conforme explica Mirla Cisne em seu livro Gênero, Divisão Sexual do Trabalho e Serviço Social, por forte "influência de feministas e acadêmicas" (CISNE, 2015, p.85) e com principal objetivo de desconstruir e desnaturalizar as desigualdades entre homens e mulheres, presentes hoje em nossa sociedade. A autora destaca que quando se discute o termo gênero, ele muitas vezes é associado à mulher, no sentido biológico, de sexo. Nessa perspectiva, o entendimento sobre a mulher passa a ser pensado como uma construção histórica e social, frágil, feminina (o que é ser feminina?), delicada, protetora, acolhedora, cuidadora.

No avanço sobre essas questões, Cisne (2015) aborda a opressão de gênero, masculino sobre o feminino, tanto na força física, como na questão moral, social e financeira. Opressões essas construídas e fomentadas historicamente. A autora afirma que as feministas de base materialista histórica mar- 
xista, fomentavam o uso de "relações sociais de sexo" (CISNE, 2015, p. 90), que envolviam antagonismo e conflitos nas mais diversas hierarquias sociais, em diferentes grupos, de homens e mulheres. Nessa medida, para esse grupo, o sexo também é motivo de discussão e é fruto de uma construção social.

Saffioti (1992) acredita que o gênero é uma categoria analítica relacional e propõe a formulação do conceito de relações de gênero ao afirmar que

O conceito de relações de gênero deve ser capaz de captar a trama de relações sociais, bem como transformações historicamente por ela sofridas através dos mais distintos processos sociais, trama esta na qual as relações de gênero têm lugar (Saffioti, 1992, p. 187).

Na medida em que as relações de gênero alargam a perspectiva para além da existência de dois sexos (masculino e feminino), abre-se a possibilidade de entender outros fatores que pressupõem relações de ordem cultural, histórico e futuro, de analisar como a pessoa é encontrada na sociedade. Para Saffioti (1992, p. 190), o género é construído e expresso por meio de relações sociais. A autora também salienta que existem semelhanças e diferenças de classe nas relações de gênero, e que essas são historicamente constituídas.

É então nesse contexto, que Cisne (2015) apresenta sua discussão em relação a gênero e divisão sexual do trabalho, em relação às construções históricas e sociais que envolvem o termo, e todo o peso que recai com ele sobre as pessoas. Gênero difere de sexo, pois vislumbra essas características sociais e culturais, construídas historicamente, e que não se delimitam por sexo, biológico. Para além, nesse artigo trabalharemos sobre gênero e Serviço Social, perpassando a história da profissão assistente social e sua relação com o gênero feminino.

\section{ASPECTOS RELACIONADOS A GÊNERO E SERVIÇO SOCIAL}

O Serviço Social no Brasil origina-se na década de 1930, por meio de encontros das damas de caridade, vinculadas à igreja católica e à elite brasileira. Essas mulheres de boa aparência, de benesse latente, tinham o objetivo de ajudar os menos favorecidos, pobres, proletários e pessoas em condições insalubres. O Serviço Social surge nesse país como forma de agregar a manutenção da ordem, ou seja, as benfeitorias das damas de caridade serviriam para acalentar aqueles e aquelas que não tinham o necessário para sobrevivência.

Assim, o Serviço Social, vem para cobrir uma lacuna em detrimento da ausência do Estado, em relação às políticas públicas e sociais que de fato consolidassem o mínimo para manutenção e subsistência da classe trabalhadora e da que não se encontrava nesse nicho, mas sim às margens da sociedade. Nesse contexto, as benfeitorias das senhoras de elite, eram mais uma vez papel 
GÊNERO E SERVICCO SOCIAL NA RÁDIO UNIVERSIDADE:

A EXPERIÊNCIA POR MEIO DO PROGRAMA "SOCIAL EM QUESTÃO"

da mulher, subordinada na sociedade e criada como cuidadora, detentora da bondade, do zelo. Dessa maneira, com o tempo surgiram as primeiras escolas de Serviço Social, na sua maioria voltadas para o público feminino. Somente após o Movimento de reconceituação na década de 1980 e da ruptura do Serviço Social com o conservadorismo na década de 1990, a profissão Assistente Social foi regulamentada pela Lei 8.662/1993 e Código de Ética de fato comprometido com a classe trabalhadora. Esses eventos vieram a consolidar a profissão de assistente social como parte da divisão sócio técnica da categoria trabalho, porém, ainda na manutenção de sua hegemonia feminina.

Essa hegemonia feminina pode ser compreendida por meio da lógica do patriarcado. Esse sistema de dominação e exploração sobre as mulheres, que faz parte do sistema capitalista, no Serviço Social, e em outras profissões como enfermagem, docência, pedagogia, essa lógica seguiu a mesma, nos primórdios da profissão. São profissões diretamente relacionadas ao gênero feminino, em que pressupõe-se, historicamente, que mulheres são mais dadas aos cuidados, compreensão e vocação maternal. A ruptura com o conservadorismo, os movimentos feministas e a desconstrução necessária do patriarcado, mesmo em partes, é o que altera esse quadro parcialmente. Pois hoje, a profissão, ainda é predominantemente feminina em todo Brasil.

Trazer a contextualização histórica para a realidade cotidiana, do curso de Serviço Social, na Universidade Federal de Santa Maria - UFSM, o qual iniciou suas atividades no segundo semestre do ano de 2010, apresenta visivelmente essa hegemonia de estudantes mulheres, o que corrobora com o caráter histórico de uma profissão feminina, apesar dessa realidade vir transformando nos últimos anos e estar em constante transformação. Existem seis núcleos de estudos, pesquisa e extensão, ligados ao serviço social, que abordam temáticas diversas. Entre eles, o Núcleo de Estudos, Pesquisa e Extensão em Serviço Social, Mídia, Cultura e Questão Social (NEPMQS) que desenvolve atividades de extensão, nas quais se destacam: Fórum de Mídia e Questão Social, evento anual que contempla as abordagens entre mídia, questão social e também expressões culturais; a roda de debates "Conversa com" que teve sua primeira edição em maio do corrente ano, propiciando um espaço para participação da comunidade universitária de forma livre e democrática e o pioneiro Programa "Social em Questão", programa radiofônico transmitido semanalmente pela Rádio Universidade 800AM desde 2015.

No programa "Social em Questão" são abordados assuntos relacionados aos direitos de cidadania e políticas públicas, perpassando uma ampla diversidade de assuntos. A temática sobre gênero entra nessa discussão de maneira transversal a todos os temas vinculados ao núcleo. 


\section{O DEBATE SOBRE GÊNERO POR MEIO DO PROGRAMA SOCIAL EM QUESTÃO}

O Programa Social em Questão é veiculado todas as segundas feiras às $13 \mathrm{~h} 10$ na Rádio Universidade 800AM. Após sua transmissão, os áudios ficam disponíveis, para audição ilimitada, na Radiotube'. O "Social em Questão" pelo segundo ano consecutivo, recebe recursos do Fundo de Incentivo à Extensão (FIEX), proporcionando o financiamento de bolsas acadêmicas para a condução de todas as atividades ligadas a essa proposta de extensão universitária.

Inicialmente, o "Social em Questão" pretendia divulgar os trabalhos dos núcleos de estudo, pesquisa e extensão, principalmente os vinculados ao curso de Serviço Social UFSM e assuntos vinculados à temática de estudos e pesquisa do NEPMQS. Com o tempo, e o aprimoramento desse projeto, o mesmo transpôs o arco da UFSM e aproximou-se da comunidade não acadêmica. Nessa construção, assegura-se que pessoas envolvidas com grupos, movimentos sociais, órgãos públicos, espaços privados e outras que estejam relacionadas ao serviço social, mídia, cultura e questão sejam chamadas para gravar e falar sobre as atividades desenvolvidas.

Desde 2015, as temáticas de gênero estiveram presentes em nove programas, transmitidos pelo "Social em Questão". A dimensão da importância da comunicação e do rádio, especificamente do Programa para levar informação de qualidade e de forma nítida para a comunidade em geral, pode ser mais bem compreendida pela elucidação de Marilena Chauí, no trecho que segue

Os primeiros estudos sociológicos, psicológicos e filosóficos sobre os meios de comunicação de massa foram feitos a partir da expansão das ondas de rádio. Mais do que o telefone, o telégrafo sem fio e o fonógrafo, o rádio despertou interesse porque com ele iniciaram-se efetivamente a informação e a comunicação de massa a distância. Sua importância e seu impacto podem ser avaliados com o caso da transmissão radiofônica de A guerra dos mundos, feita por Orson Welles. (CHAUÍ, 2006, p.44)

Chauí (2006) define a grandeza do alcance do rádio para a comunicação de massa, para levar informação aonde outros meios de comunicação não chegam. Nesse sentido, mostra-se a importância de discutir e debater temas como "gênero" no Programa "Social em Questão", de levar informação de qualidade e que se faça entender para além da universidade.

Nessa perspectiva, Guareschi e Biz (2017) trazem como fundamental o direito à informação e à comunicação e que na Declaração Universal dos Direitos do Homem de 1948, no artigo 19 está posto que,

$\overline{1}$ Site colaborativo feito por e para comunicadores, que comporta produções radiofônicas de todo o Brasil. Disponível em < https://www.radiotube.org.br >. 
GÊNERO E SERVICCO SOCIAL NA RÁDIO UNIVERSIDADE:

A EXPERIÊNCIA POR MEIO DO PROGRAMA "SOCIAL EM QUESTÃO"

Todo o homem tem direito à liberdade de opinião e expressão; esse direito inclui o de não ser molestado por causa de suas opiniões, o de investigar e receber informações e opiniões e o de difundi-las, sem limitação de fronteiras, por qualquer meio de expressão. (GUARESCHI; BIZ, 2017, p. 115)

Guareschi e Biz (2017) afirmam que esse artigo especifica o direito ao acesso à informação, de qualidade, imparcial e em todos os lugares além do direito à comunicação, que consiste em expressar opiniões, pensamentos, por quaisquer meios. Nisso, fazem um resgate acerca do rádio como meio de comunicação de massa e de como seu uso, atualmente, é subestimado em detrimento de outros meios como televisão e mídias sociais. Ressaltam a vantagem de que o mesmo pode ser transportado para diversos lugares, em vários tamanhos e sem necessidade de energia elétrica para funcionamento, tratando de rádio a pilha. Ainda é destacado o fato de o mesmo ser companhia nos mais diversos tipos de trabalho, desde a grande fábrica até o serviço doméstico. O mesmo leva música, entretenimento, informação e essa informação, por direito, deve ser de qualidade e de maneira que se faça entender por seu público ouvinte.

A comunicação e o serviço social andam lado a lado no Núcleo de Estudos, Pesquisa e Extensão em Serviço Social, Mídia, Cultura e Questão Social (NEPMQS), no programa radiofônico "Social em Questão", "Fórum de Mídia", "Conversa Com" e para além, no fazer profissional do e da assistente social. Pois é por meio da comunicação que o assistente social estabelece vínculo com os e as usuárias, faze encaminhamentos para a rede de atendimentos, que compreende diversos serviços, e é por meio da comunicação que o e a assistente social transpõe as barreiras culturais e estruturais, e consegue assim, aproximar-se dos sujeitos e oportunizar atendimentos que fomentem a autonomia e a emancipação dos mesmos.

\subsection{Programas "Social em Questão" sobre gênero}

Desde 2015, foram nove programas que trataram assuntos relacionados diretamente à temática de gênero, apesar de compreendermos que gênero perpassa todos os espaços e programas já veiculados no "Social em Questão", está relacionada com todos os lugares e assuntos. Segue tema, data de transmissão, link para audição da Radiotube e breve síntese de cada um dos nove programas selecionados para esse artigo. 


\begin{tabular}{|c|c|c|}
\hline Pauta & Síntese & $\begin{array}{l}\text { Transmissão e link para audição na } \\
\text { Radiotube }\end{array}$ \\
\hline \begin{tabular}{|l|} 
Tese de Doutorado \\
"Telenovelas y Políticas \\
Públicas de Género em \\
Brasil: uma análisis a partir \\
de las mujeres em situación \\
de riesgo social" \\
\end{tabular} & $\begin{array}{l}\text { Tese de doutorado em andamento, que investiga } \\
\text { como as telenovelas interferem nas percepções } \\
\text { sobre políticas públicas de mulheres em situação } \\
\text { de risco. }\end{array}$ & $\begin{array}{l}\text { Transmissão: 29/06/2016 } \\
\text { Bloco 01: https://www.radiotube.org.br/ } \\
\text { audio-44859|j9WONbk } \\
\text { Bloco 02: https://www.radiotube.org.br/ } \\
\text { audio-4485bBPSxhHVQ }\end{array}$ \\
\hline $\begin{array}{l}\text { Núcleo de Estudos, } \\
\text { Pesquisa e Extensão em } \\
\text { Gênero, Políticas Sociais e } \\
\text { Movimentos Sociais }\end{array}$ & $\begin{array}{l}\text { O tema central foi o trabalho desenvolvido no } \\
\text { núcleo, com foco nas discussões sobre gênero, } \\
\text { políticas sociais e movimentos sociais e a } \\
\text { importância do debate dentro da Universidade. }\end{array}$ & $\begin{array}{l}\text { Transmissão: 13/07/2017 } \\
\text { Bloco 01: https://www.radiotube.org.br/ } \\
\text { audio-44856ELSbedMN } \\
\text { Bloco 02: https://www.radiotube.org.br/ } \\
\text { audio-4485S6t8FkfZk }\end{array}$ \\
\hline $\begin{array}{l}\text { Marcha Mundial das } \\
\text { Mulheres }\end{array}$ & $\begin{array}{l}\text { Mulheres integrantes do Núcleo Marias da Silva } \\
\text { da Marcha Mundial das Mulheres e falaram } \\
\text { sobre o movimento feminista e questões de } \\
\text { gênero. O Núcleo Marias da Silva é de Santa } \\
\text { Maria - RS. A MMM nasceu no ano } 2000 .\end{array}$ & $\begin{array}{l}\text { Transmissão: 21/09/2015 } \\
\text { Bloco 01: https://www.radiotube.org.br/ } \\
\text { audio-448573uw4ax6D } \\
\text { Bloco 02: https://www.radiotube.org.br/ } \\
\text { audio-448500X2zzjFl }\end{array}$ \\
\hline $\begin{array}{l}\text { Movimento LGBT e Serviço } \\
\text { Social }\end{array}$ & $\begin{array}{l}\text { Movimento LGBT e o Serviço Social e as } \\
\text { questões de gênero inerentes à temática }\end{array}$ & $\begin{array}{l}\text { Transmissão: 03/06/2016 } \\
\text { Programa na íntegra: https://www. } \\
\text { radiotube.org.br/audio-4485A1xVPmTX9 }\end{array}$ \\
\hline Violência de Gênero & $\begin{array}{l}\text { Violência de gênero, feminismo e } \\
\text { empoderamento feminino. }\end{array}$ & $\begin{array}{l}\text { Transmissão: 03/10/2016 } \\
\text { Programa na íntegra: https://www. } \\
\text { radiotube.org.br/audio-4485H1V40ampN }\end{array}$ \\
\hline Coletivo VOE & $\begin{array}{l}\text { Histórico dos movimentos LGBT e da II Parada } \\
\text { Alternativa LGBT de Santa Maria, onde a } \\
\text { questão de gênero está presente. } \\
\end{array}$ & $\begin{array}{l}\text { Transmissão: 28/11/2016 } \\
\text { Programa na íntegra: https://www. } \\
\text { radiotube.org.br/audio-4485RSx9bvJT0 }\end{array}$ \\
\hline Aborto Legal & $\begin{array}{l}\text { Integrantes da Equipe de Matriciamento } \\
\text { atendem vítimas de violência sexual, a equipe } \\
\text { e o hospital são referências na região. Está } \\
\text { caminhando para ter o procedimento de aborto, } \\
\text { nos casos previstos em lei, no HUSM, o qual só é } \\
\text { realizado em Porto Alegre. }\end{array}$ & $\begin{array}{l}\text { Transmissão: 06/03/2017 } \\
\text { Programa na íntegra: https://www. } \\
\text { radiotube.org.br/audio-4485qlaEey8kE }\end{array}$ \\
\hline Mulheres no HIPHOP & $\begin{array}{l}\text { Abordou a violência de gênero dentro do } \\
\text { movimento Hip-hop, a opressão sofrida por } \\
\text { essas e outras mulheres que se reorganizaram } \\
\text { e criaram um espaço onde pudessem cantar } \\
\text { somente entre mulheres. É um movimento } \\
\text { de resistência dentro de um movimento de } \\
\text { resistência. }\end{array}$ & $\begin{array}{l}\text { Transmissão: 24/04/2017 } \\
\text { Programa na íntegra: https://uww. } \\
\text { radiotube.org.br/audio-44850GZD8mCR4 }\end{array}$ \\
\hline $\begin{array}{l}\text { Grupo de Vivências } \\
\text { LGBTQIA UFSM }\end{array}$ & $\begin{array}{l}\text { Abordou a temática de gênero, sobre a } \\
\text { comunidade LGBTQIA, seus desafios cotidianos } \\
\text { e sobre o Grupo de Vivências LGBTQIA que } \\
\text { ocorre semanalmente na UFSM. }\end{array}$ & $\begin{array}{l}\text { Transmissão: 05/06/2017 } \\
\text { Programa na íntegra: https://www. } \\
\text { radiotube.org.br/audio-4485b0CB6D7g7 }\end{array}$ \\
\hline
\end{tabular}

Fonte: sistematização das autoras.

A tabela acima possibilita a ilustração dos programas e a diversidade das abordagens veiculadas por meio do programa radiofônico Social em Questão. Acredita-se que ao se abrir espaços como esse, proporciona-se um processo de informação e conscientização da comunidade em geral, para novas possibilidades de conceitos e perspectivas de interpretar a realidade. 


\section{CONSIDERAÇÕES FINAIS: A IMPORTÂNCIA DE FALAR SOBRE GÊNERO NA RÁDIO}

Falar sobre gênero para o Núcleo de Estudos, Pesquisa e Extensão em Serviço Social, Mídia, Cultura e Questão Social (NEPMQS) significa compreender que esse conceito está imbricado em todas as temáticas que abrangem não só o núcleo, como também, o curso de Serviço Social na sua totalidade.

Falar, debater e desconstruir mitos relacionados a gênero, como, por exemplo, associar gênero a expressão apenas as mulheres, é dever e parte do cotidiano do núcleo e do Serviço Social. Para além dos espaços sócios ocupacionais e das salas de aula da universidade, debater a temática de gênero é fundamental no fazer profissional e no dia a dia da luta por direitos e igualdade. Não é possível pensar uma sociedade mais justa e igualitária, sem que tenhamos igualdade de gênero, no tratamento, nas funções, no salário e no respeito.

Por fim, considera-se que é função social da universidade, levar esse debate para a comunidade e é dever do e da profissional assistente social, lutar por uma sociedade mais justa, por uma garantia e ampliação de direitos já conquistados e por novos direitos que permitam que a comunidade feminina seja tratada e tenha acesso aos mesmos direitos que a masculina, o que historicamente não é respeitado e permitido.

\section{REFERÊNCIAS}

CHAUÍ, Marilena. Simulacro e poder: uma análise da mídia. São Paulo: Fundação Perseu Abramo, 2006.

CISNE, Mirla. Gênero, Divisão Sexual do Trabalho e Serviço Social. $2^{a}$ edição - São Paulo: Outras Expressões, 2015. 152 p.

GUARESCHI, Pedrinho A.; BIZ, Osvaldo. Mídia, educação e cidadania: para uma leitura crítica da mídia. Porto Alegre. Evangraf, 2017.

SAFFIOTI, Heleif. Rearticulando gênero e classe social. In: COSTA, Albertina de Oliveira; BRUSCHINI, Cristina (Org.). Uma questão de gênero. Rio de Janeiro: Rosa dos Tempos; São Paulo: Fundação Carlos Chagas, 1992. 